\title{
APPLICATION OF THE ANALYTIC HIERARCHY PROCESS TO THE SOCIOLOGICAL ANALYSIS
}

\author{
Antonio Maturo \\ Department of Social Sciences \\ University of Chieti-Pescara \\ Italy \\ E-mail: amaturo@unich.it \\ Rina Manuela Contini \\ Department of Social Sciences \\ University of Chieti-Pescara \\ Italy \\ E-mail: rm.contini@unich.it
}

\begin{abstract}
In this research the Analytic Hierarchy Process is applied to analyze the complex problems related to the social field, as, for example, the phenomenon of foreign students' school integration, a phenomenon that is simultaneously considered complex and multidimensional by all the most recent literature. For this purpose a case study is presented, in which we have interviewed twelve teachers of a primary school. The opinions of each of these teachers are represented with three pairwise comparisons matrices: the matrix of paired comparisons of the sub-objectives with respect to the general objective, and the two matrices of paired comparisons of a set of variables with respect to every sub-objective. Precisely, starting from the definition of the general objective "foreign students' school integration", two sub-objectives have been single out: "the interpersonal communication" and "the degree of scholastic profit". Furthermore nine variables B1, B2, ..., B9, have been introduced, in order to give an implicit definition of the general objective and of the sub-objectives. Furthermore, with Saaty's AHP method, for every interviewed teacher, pairwise comparisons matrices are compiled. In order to give a group evaluation of opinions of teachers, for every set of homogeneous matrices, two summarizing matrices are introduced, the geometric mean $\mathrm{G}$, and the uncertainty multiplicative index $\mathrm{U}$. Matrices $\mathrm{G}$ and $\mathrm{U}$ are utilized to assign fuzzy triangular scores to sub-objectives, and to variables with respect to every sub-objective. In order to obtain the cores of such fuzzy scores, two criteria are considered and compared, the first one based on a weighted arithmetic mean of the columns of $\mathrm{G}$, the second one based on eigenvalues and eigenvectors. As a significant social meaning, it has emerged from the results obtained that the interpersonal communication is resulted far more important than the degree of scholastic profit. Moreover, variables concerning relation and interaction capacity are dominant with respect to variables concerning school, sport or manual abilities.
\end{abstract}

Keywords: Social complex systems and phenomena, pairwise comparisons matrix, AHP method, fuzzy numbers, uncertainty indices.

\section{Complex social problem of scholastic integration of foreigners}

It is our intention in this study to propose the use of fuzzy logic to study complex social problems, in order to define new models of sociological analysis. 
An important example of complex social phenomena is given by the scholastic integration of children and adolescents with a migration background. This issue is particularly relevant to Western societies which are undergoing significant changes. These changes are due to globalisation processes and mobility of people and groups across national boundaries (Bauman 1999a; Cesareo, 2008: pp.30-31). Western societies are characterized by the progressive consolidation of their multiethnic aspect. Moreover they are shaped by conflicting forces between the recognition of the differences on the one hand and the creation of social integration on the other. Most scholars concentrate on the analysis of the relation between global and local culture, as well as on the relationships that run between globalization and ethnicity of the conflicts between cultures (see, in particular: Featherstone, 1998, pp.46-51; Cesareo, 1997, p.266 ssgg., 2004, 2006; Geertz, 1999, p.19 ssgg.; Hannerz, 1996, p.163 ssgg.; Smith, 1990; Featherstone, 1996, p.9 ssgg.; Fabietti, 1995; Kristeva, 1990, p.178 sgg.; Besozzi, 1999, p.24 ssgg.; Bauman, 1999a, 1999b, 2001; Bovone, Rovati, 1996; Giddens, 1994; Simmel, 1983; Sgritta, 1997; Besozzi, 2001, p.66). The school is at the core of the matter of the contemporary debate over the cultural interaction of different cultures. Indeed, the school "performs a strategic function in building a future of inevitable inter-ethnic cohabitation», as well as «in the acquisition of the abilities necessary for the economic and political integration of tomorrow's citizens» (Ambrosini, 2008b:10-11). The formative and socialization processes at school provide the basis for accessing public space and social resources: «the school is therefore the symbolic place where the evolution of complex societies is vividly represented; to study the school means to study society» (Fravega, 2003, p 8). In other words, integration is an intentional project, that doesn't occur by chance, but it requires organized strategies and action. In the debate on integration, E. Besozzi sees a connection of interdependence between the concepts of identity and diversity, and the concepts of integration (assimilation, tolerance-inclusion, and relationship-exchange) and the intervention strategies (Besozzi, 1999: 26; 2001: 73). In the International debate different epistemological positions are recognized: these are at the basis of different concepts of integration and of different applications in the political ambit. These can be of assimilation and multiculturalism ${ }^{1}$. This, of course, applies to all literature, but to the American one to an even greater extent, as a new edition of the neo-assimilation theory (Alba-Nee, 1997) has been made. This vision allows «the normative and ethnocentric assumptions of the assimilation vision to fall, but confirms that the assimilation continues to happen in the passage from a generation to the other through language learning, dispersion in different ambits of the job market, mixed marriages, and so on » (Ambrosini, 2008b: 2).

\footnotetext{
${ }^{1}$ The main interpretive paradigms concerning integration are: the theories of assimilation, that constitute the theoric background of most of the research on integration and the Cultural Studies. The assimilation theory, elaborated by the School of Chicago and strengthened with time, derives from the universal epistemological perspective. This is based on the idea that a common universal horizon exists - the human kind - able to contain all the differences. From this point of view, assimilation is a process that inevitably takes place at a generational level, as the encounter with the other is realized through the assimilation in time to the dominant cultural model. From the universal theory also derives the political models of the management of the interethnic living together that are defined assimilationist, like for example the French or American model (see Gilardoni's considerations, 2008:pp.13-32). The Cultural Studies start from the critic to ethnocentrism of the assimilation theories and focus on the concept of the specific nature of each culture. Furthermore, many scholars recognise in the differentialist perspective the risk of relativism. At present, the need to find new explicative perspectives leads to take into consideration the intercultural model. This model tries to overcome the limits of assimilation and differentiation theories maintaining at the same time the merits (Gilardoni, 2008:28). This is characterized by a plurality of relations and exchanges between different cultures, but always based on the sharing of a nucleus of inalienable values. (Cesareo, 2008: 29-31). In the panorama of social sciences the trans-national perspective stands out too. This perspective of analysis wants to go beyond the "methodological nationalism" - that implicitly overlaps the National State to society and invites to think of integration as identification with the National State (Beck, 2003). Further, the trans-national perspective analyses the migrations as experiences of globalization from below that is to say like the globalisation of common people, and takes into consideration all the ties that exist on a social, economic and cultural level beyond the National borders (Ambrosini 2007a; 2007b; 2008a, chapter I and chapter II).
} 
Portes and Rumbaut $(2001 ; 2005 ; 2006)$ have distanced themselves both from bumby-line assimilation theories presented by Alba and Nee (1997) and from the assimilation paradigm as a linear process reintroduced by Perlman and Waldinger (1997). They suggested the segmented theory of assimilation that takes into account upward, selective and downward assimilation paths.

The segmented assimilation theory takes into account the socio-economic conditions within which the integration is carried out, highlighting the way in which the integration takes place in a particular social segment. In other words, the second generation of immigrants may follow different paths: on one hand life trajectories that develop along a path of ascending mobility, such as the upward assimilation and the selective assimilation, through which they enter the American society mainstream; on the other hand, instead, there are paths of descending mobility, the so called downward assimilation. "The assimilation process is therefore subdivided in paths that can be of upward mobility or downward mobility. Such forms depend on both social and individual elements» (Gilardoni, 2008: 21), that are formed by: the hospitality contest; the incorporation modalities of the hosting society; the modalities through which the intergenerational relations are delineated; the available resources in the family - such as the human capital in the families; the migratory history.

So, all the most recent literature considers the concept of scholastic integration as complex, multidimensional, gradual, and contextual. The Scholars agree that the concept of school integration has to do both with the acquisition of abilities, competences and knowledge, and with the relationships between adults and peers at school and outside school (Giovannini and Queirolo Palmas 2002: 190; Cesareo, 2001; Besozzi, 1999; 2001; 2005; Giovannini, 1996; 2001; 2006; Fravega and Queirolo Palmas, 2003). Concluding their research on the scholastic experiences in cross-cultural contexts, Giovannini and Queirolo Palmas underline that in the future research it is «necessary to exit from the binary logic national/non national and to focus on the internal differences, the migratory trajectories, the migrants biographies ..., that is necessary to consider the internal heterogeneity and the contextual character of any integration process» (Giovannini and Queirolo Palmas 2002: 190). To comprehend the scholastic integration in its complexity means to consider different levels connected.

A first series of factors affecting the trajectories of inclusion of foreign pupils and their scholastic performances are structural data like age, sex, socio-cultural status of the belonging family, national components, family migration projects; educational styles; education levels of the parents; etc. As concerns the gender-distinction, most recent research suggests that boys and girls are the addressers of different educational messages within the family, based on the different countries of origin. In regards to age, the research conducted highlights that the younger the student is when he/she begins school the easier it will be for him/her to integrate. In particular, in Rumbaut's research, that is centred on the integration processes of pupils recently immigrated, suggest that the integration path is helped in the case that the pupils are born in the host country or that arrived during the first years of their life (Rumbaut, 1997; Ambrosini and Molina, 2004; Barbagli, 2006). Many research studies show how the migration project of the family can have a deep influence on the maintenance of heritage culture of the country of origin (Favaro, Colombo, 1993; Barbagli, 2006). The research on the theme highlights how families who want to stay in the welcome country are inclined to comply to the customs of the welcome country, while the families who have the perspective of returning to their native country are likely to keep their own culture and customs. Indeed, it is possible to register different ways of immigration paths: "male", "female", "simultaneous", and "multiple", "organized"2. Both the immigration paths and migration

\footnotetext{
${ }^{2}$ In the case of "male" emigration - which sees the head of the family emigrating for first- and the "female" one, the family reunion with wife/husband and the children happens only after some time. These paths are accompanied by other simultaneous ones, in which the couple emigrate together, while the departure of the children can be postponed. The multiple paths are marked by long sequence of movements to look for job. Finally, the organized migration paths are characterized by the establishment of a solid migration chain that takes into account the direction of the migration from the country of origin directly and firmly in a particular city. Regarding this, see: Favaro, Colombo, 1993; Barbagli, 2006.
} 
projects of the family are related to the different origins of ethnic groups and highlights different strategies of maintenance of familiar-cultural heritage. As is shown in the research (see, e.g., Favaro, Colombo, 1993; Barbagli, 2006), immigrants who intend to stay in the host country, as in the case of Albanian families, are eager to conform to the culture and values of the welcome country and to not emphasize the transmission of their native cultural values to their own children. On the contrary, African immigrants tend to return home, and therefore African families maintain cultural traits essentially unaltered. Some research highlights how the national origin of the parents influences shared values and the mutual behaviour expectations ${ }^{3}$. Portes and Rumbaut in their research (2001), also showed that the parent's National origin turned out to be one of the predictive variables of the scholastic integration of the scholastic performances of second generation. In the study carried out by Tribalat (1995) on the scholastic paths of the foreign students in France it was found that groups of Algerian and Moroccan students, although a thorough knowledge of the language, face major difficulties in the schooling path and gain worse marks than those obtained by groups of Portuguese students. As concerns the cultural level of the families, Portes and Rumbaut (Portes and Rumbaut 2001; Fravega 2003) highlight that the level of education of the parents is positively linked to their children's scholastic success and with the building of social networks. The research carried out by Farley and Alba determines the parents' education as a principal explicative factor of differences in the scholastic profit of children. In this view, it appears that also the mother tongue fluency positively affects the scholastic performance (Portes and Hao, 2002; Hakuta, 1986; Tribalat, 1995; Portes and Rumbaut, 2001; Giovannini and Queirolo Palmas, 2002; Barbagli, 2006). So, on the basis of the available research, «it can be stated that the parents' level of education is the most important predictive value of scholastic success, both for second generation and for the native population» (Ambrosini, 2008b: 2).

Another element of interest is given by the international debate: the maintenance, suitably re-elaborated and adapted, of minority identity-making traits is not necessarily an obstacle to social integration, but it can be an explicative factor of scholastic success in second generations. Portes and Rumbaut's research (2001) and Zhou's (1997) highlight how the connection with the ethnic community can contribute significantly to overcome the structural disadvantages of the immigrants and promote inclusion.

A second series of factors that explain the process of scholastic integration are: the functioning of the receiving society's school system; the material and non material investments in the scholastic field; the specific resources and projects promoted by the scholastic institutions; the dialogue between school and students with a different linguistic and cultural background and the value given to intercultural education.

\footnotetext{
3 The nationality can lead to a poor knowledge of the rules due to the different roles that the family and the school can have in the culture of origin and in the host one. For example, in the Chinese culture and in the Moroccan one the school does not require an active participation of the parents to the scholastic life of the children, because school has the control over the educational duties, and the teacher is seen an authoritative figure that is very respected by the parents. Within this cultural specific nature, the distance that the immigrant families have towards the scholastic context can be read as a sign of confidence in the institutions, of non interference towards the teachers and not as an excessive way of protecting their own culture or lack of interest towards the school. Another factor that can determine a reason of distance from the scholastic world is the perception of a discontinuity between the values passed down by the families and those spread by the school (Dubet-Martuccelli, 1996). Another difficulty can be determined from the perception of discrepancy between the attention of our school dedicated to the development of independence, critical abilities, individual creativity and the importance that other different cultures give to the repetition-memorizing process, to the continuity between generations, to the sense of hierarchy and dependence, to the respect and distance between adults and young people. (Favaro, 1998; Demetrio-Favaro, 2000).
} 


\section{Analysis of the "foreign students' scholastic integration" problem with the AHP method}

Our aim is to analyse the complex phenomenon of scholastic integration. The mathematical tools are the AHP procedure, the fuzzy logic, and fuzzy arithmetic. Our purpose is to elaborate methods that allow us to represent the complexity of the phenomenon, and to underline non-detectable aspects, on an intuitive and qualitative level.

Such an application is justified by the fact that the fuzzy logic is appropriate for dealing with complex phenomena and is successful in providing a mathematical formalization; moreover, recent results obtained in the research on fuzzy systems can be applied effectively to the empirical sociological observation where the uncertainty in data is often of a semantic kind. On the basis of the fuzzy approach, finally, complexity is represented as a form of uncertainty, and methods to deal with such uncertainty are elaborated.

The complex phenomenon of the foreign students' scholastic integration is analyzed with the Analytic Hierarchy Process. The AHP creates a method of analysis useful in the economic sciences and social sciences, in particular in situations in which it is necessary to decide the order of priority in which we have to place $n$ satisfactory alternatives, in different measures, having prescribed choice criteria. This means that AHP treats the problem of ranking alternatives, that is, giving their alignment, in order of preference or importance on the basis of (quantitative) valuations.

In our research, we start from the idea that the general objective (GO) of the analysis is "the foreign students' scholastic integration" and that, referring to the scientific literature on the topic, it is divided into two particular sub-objectives:

- $\mathrm{A} 1$ = interpersonal communication;

- $\mathrm{A} 2$ =the degree of scholastic profit.

With the AHP procedure to each one of these sub-objectives is associated a weight with respect to the general objective.

Moreover, a set of variables has been determined which allow us to give an implicit definition of the general objective. The variables considered are:

- $\quad \mathrm{B} 1=$ interaction and relations in class with peers;

- $\quad \mathrm{B} 2=$ relations in the extra-curricular time;

- $\quad \mathrm{B} 3$ = interaction and relations in class with teachers;

- $\quad \mathrm{B} 4=$ relations with the belonging environment;

- $\quad$ B5 = linguistic-expressive abilities;

- $\quad$ B6 = logic-mathematical abilities;

- $\quad$ B7 = manual skills;

- $\quad$ B8 = group activities;

- $\quad$ B9 = sport skills.

A questionnaire has been given to a group of 12 teachers in a primary school in Pescara, where the problem of "the foreign students' scholastic integration" is particularly felt. The teachers considered are very expert and interested in the problem, and then they can be considered privileged observers. Every teacher $T^{(r)}, r=1,2, \ldots, 12$ is requested to compile three matrices of pairwise comparisons:

1. The matrix $\mathrm{A}^{(\mathrm{r})}$ of the sub-objectives $\mathrm{A} 1$ and $\mathrm{A} 2$;

2. The matrix $\mathrm{M}^{(\mathrm{r})}$ of the variables $\mathrm{B} 1, \mathrm{~B} 2, \ldots, \mathrm{B} 9$, with respect to sub-objective $\mathrm{A} 1$;

3. The matrix $\mathrm{N}^{(\mathrm{r})}$ of the variables B1, B2,.., B9, with respect to sub-objective A2.

The approach is the one considered in the Analytical Hierarchy Process (Saaty, 1980; Saaty, and Peniwati, 2007; Saaty, 1980). Let $\mathrm{X}_{1}, \mathrm{X}_{2}, \ldots, \mathrm{X}_{\mathrm{m}}$ be the objects to compare (e.g., sub-objectives or variables). Every teacher $T$, if considers $X_{i}$ preferred or indifferent to $X_{j}$, then is requested to estimate the importance of $\mathrm{X}_{\mathrm{i}}$ with respect to $\mathrm{X}_{\mathrm{j}}$ using one of the following judgments: indifference, weak preference, 
preference, strong preference, absolute preference. The judgment chosen is said to be the linguistic value associate to the pair $\left(\mathrm{X}_{\mathrm{i}}, \mathrm{X}_{\mathrm{j}}\right)$. Then the linguistic values are expressed as numerical values following the Saaty fundamental scale:

- $\quad$ indifference $=1$,

- $\quad$ weak preference $=3$,

- $\quad$ preference $=5$,

- $\quad$ strong preference $=7$,

- $\quad$ absolute preference $=9$.

The scores 2, 4, 6, 8 are used for intermediate valuations.

If the object $X_{i}$ has one of the above numbers assigned to it when compared with object $X_{j}$, then $X_{j}$ has the reciprocal value when compared with $X_{i}$.

Then a pairwise comparisons matrix $A=\left(a_{i j}\right)$ with $m$ rows and $m$ columns is associated to the $m$-tuple $\left(\mathrm{X}_{1}, \mathrm{X}_{2}, \ldots, \mathrm{X}_{\mathrm{m}}\right)$, where $\mathrm{a}_{\mathrm{ij}}$ is the number assigned to $\mathrm{X}_{\mathrm{i}}$ when compared with $\mathrm{X}_{\mathrm{j}}$.

\section{A synthesis of judgments with fuzzy numbers}

The purpose of our research is to determine the critical variables; in other words, the variables that have the greatest effects on the degree of scholastic integration.

A group of twelve motivated teachers, $\mathrm{T}^{(\mathrm{r})}, \mathrm{r}=1,2, \ldots, 12$, have supported the initiative expressing their own ideas, each one filling in three matrix $A^{(r)}=\left(a_{i j}{ }^{(r)}\right), M^{(r)}=\left(m_{i j}^{(r)}\right), N^{(r)}=\left(n_{i j}{ }^{(r)}\right)$.

Let $\mathrm{Y}^{(\mathrm{r})}=\left(\mathrm{y}_{\mathrm{ij}}{ }^{(\mathrm{r})}\right)$ denote the generic element of the set $\left\{\mathrm{A}^{(\mathrm{r})}, \mathrm{M}^{(\mathrm{r})}, \mathrm{N}^{(\mathrm{r})}\right\}$. The synthesis of the teachers' opinions is made by considering, for every each pair $(i, j)$ of indices, the following numbers:

a. the geometric mean $\mathrm{G}_{\mathrm{ij}}{ }^{\mathrm{Y}}$ of the opinions of the teachers, defined by the formula:

$$
\mathrm{G}_{\mathrm{ij}}^{\mathrm{Y}}=\left(\mathrm{y}_{\mathrm{ij}}^{(1)} \mathrm{y}_{\mathrm{ij}}^{(2)} \ldots \mathrm{y}_{\mathrm{ij}}^{(12)}\right)^{1 / 12} \text {; }
$$

b. a number $\mathrm{U}_{\mathrm{ij}}{ }^{\mathrm{Y}}$, called the index of multiplicative uncertainty of the opinions, defined by the formula:

$$
\mathrm{U}_{\mathrm{ij}}^{\mathrm{Y}}=\exp \sqrt{\frac{\sum_{\mathrm{r}=1}^{12}\left[\ln \frac{\mathrm{y}_{\mathrm{ij}}^{(\mathrm{r})}}{\mathrm{G}_{\mathrm{ij}}^{\mathrm{Y}}}\right]^{2}}{12}} .
$$

The choice of $\mathrm{G}_{\mathrm{ij}}{ }^{\mathrm{Y}}$, and $\mathrm{U}_{\mathrm{ij}}{ }^{\mathrm{Y}}$ is justified by the following interesting propositions:

Proposition 3.1. For every pair $(i, j)$, the following properties hold:

(G1) $\min _{\mathrm{r}} \mathrm{y}_{\mathrm{ij}}^{(\mathrm{r})} \leq \mathrm{G}_{\mathrm{ij}}{ }^{\mathrm{Y}} \leq \max _{\mathrm{r}} \mathrm{y}_{\mathrm{ij}}{ }^{(\mathrm{r})}$, then $1 / 9 \leq \mathrm{G}_{\mathrm{ij}}{ }^{\mathrm{Y}} \leq 9$;

(G2) $\mathrm{G}_{\mathrm{ij}}{ }^{\mathrm{Y}}=1 / \mathrm{G}_{\mathrm{ji}}{ }^{\mathrm{Y}}$.

Proof. It is an immediate consequence of formula (3.1) and the Saaty fundamental scale.

Proposition 3.2. For every pair $(i, j)$, we have:

(U1) $\mathrm{U}_{\mathrm{ij}}^{\mathrm{Y}} \geq 1$ and $\mathrm{U}_{\mathrm{ij}}^{\mathrm{Y}}=1$ iff $\mathrm{y}_{\mathrm{ij}}{ }^{(1)}=\mathrm{y}_{\mathrm{ij}}{ }^{(2)}=\ldots=\mathrm{y}_{\mathrm{ij}}{ }^{(12)}$;

(U2) $\mathrm{U}_{\mathrm{ij}}^{\mathrm{Y}}=\mathrm{U}_{\mathrm{ji}}^{\mathrm{Y}}$; 
(U3) let $\mathrm{y}_{\mathrm{ij}}{ }^{(\mathrm{p})}=\min _{\mathrm{r}} \mathrm{y}_{\mathrm{ij}}{ }^{(\mathrm{r})}$, and $\mathrm{y}_{\mathrm{ij}}{ }^{(\mathrm{q})}=\max _{\mathrm{r}} \mathrm{y}_{\mathrm{ij}}{ }^{(\mathrm{r})}$; then

$$
\mathrm{U}_{\mathrm{ij}}{ }^{\mathrm{Y}} \leq \max \left\{\mathrm{G}_{\mathrm{ij}}^{\mathrm{Y}} / \mathrm{y}_{\mathrm{ij}}{ }^{(\mathrm{p})}, \mathrm{y}_{\mathrm{ij}}{ }^{(\mathrm{q})} / \mathrm{G}_{\mathrm{ij}}{ }^{\mathrm{Y}}\right) \text {. }
$$

Proof. We have that $\ln ^{2}\left(\mathrm{y}_{\mathrm{ij}}{ }^{(\mathrm{r})} / \mathrm{G}_{\mathrm{ij}}{ }^{\mathrm{Y}}\right)=\ln ^{2}\left(\mathrm{G}_{\mathrm{ij}}{ }^{\mathrm{Y}} / \mathrm{y}_{\mathrm{ij}}{ }^{(\mathrm{r})}\right) \geq 0$, and the equality holds if and only if $\mathrm{y}_{\mathrm{ij}}{ }^{(\mathrm{r})}=\mathrm{G}_{\mathrm{ij}}{ }^{\mathrm{Y}}$. Then (U1) and (U2) follow.

Let $h=\max \left\{G_{i j}{ }^{Y} / y_{i j}{ }^{(p)}, y_{i j}{ }^{(q)} / G_{i j}{ }^{Y}\right)$. From (3.2) we have $U_{i j} \leq \exp \left(\ln ^{2} h\right)^{1 / 2}=h$.

Proposition 3.1 and 3.2 and the property of $\mathrm{U}_{\mathrm{ij}}$ to be a pure number allows us to assume as group opinion of teachers on the pair $\left(\mathrm{X}_{\mathrm{i}}, \mathrm{X}_{\mathrm{j}}\right)$ of objects the fuzzy triangular number $\mathrm{F}_{\mathrm{ij}}{ }^{\mathrm{Y}}=\left(\mathrm{G}_{\mathrm{ij}}{ }^{\mathrm{Y}} / \mathrm{U}_{\mathrm{ij}}{ }^{\mathrm{Y}}, \mathrm{G}_{\mathrm{ij}}{ }^{\mathrm{Y}}, \mathrm{G}_{\mathrm{ij}}{ }^{\mathrm{Y}} \mathrm{U}_{\mathrm{ij}}{ }^{\mathrm{Y}}\right)$, with core the geometric mean $\mathrm{G}_{\mathrm{ij}}{ }^{\mathrm{Y}}$ and endpoints obtained multiplying the core by the reciprocal positive numbers $1 / \mathrm{U}_{\mathrm{ij}}{ }^{\mathrm{Y}}$ and $\mathrm{U}_{\mathrm{ij}}{ }^{\mathrm{Y}}$, respectively. The fuzzy number $\mathrm{F}_{\mathrm{ij}}{ }^{\mathrm{Y}}$ is degenerate if and only if all teachers have the same judgments.

From matrix $\mathrm{G}^{\mathrm{Y}}=\left(\mathrm{G}_{\mathrm{ij}}{ }^{\mathrm{Y}}\right)$ a vector $\mathrm{P}^{\mathrm{Y}}=\left(\mathrm{P}_{\mathrm{i}}^{\mathrm{Y}}\right)$ is obtained as the weighed arithmetic mean of the columns of $\mathrm{G}^{\mathrm{Y}}$, where every column has as weight the reciprocal of the sum of its elements. Moreover, from matrix $\mathrm{U}^{\mathrm{Y}}=\left(\mathrm{U}_{\mathrm{ij}}{ }^{\mathrm{Y}}\right)$ a vector $\mathrm{V}^{\mathrm{Y}}=\left(\mathrm{V}_{\mathrm{i}}^{\mathrm{Y}}\right)$ is calculate as the geometric mean of the column of $\mathrm{U}^{\mathrm{Y}}$.

For every object $\mathrm{X}_{\mathrm{i}}$, we define fuzzy number associate to $\mathrm{X}_{\mathrm{i}}$ the triangular fuzzy number

$$
\mathrm{T}_{\mathrm{i}}^{\mathrm{Y}}=\left(\mathrm{P}_{\mathrm{i}}^{\mathrm{Y}} / \mathrm{V}_{\mathrm{i}}^{\mathrm{Y}}, \mathrm{P}_{\mathrm{i}}^{\mathrm{Y}}, \mathrm{P}_{\mathrm{i}}^{\mathrm{Y}} / \mathrm{V}_{\mathrm{i}}^{\mathrm{Y}}\right) \text {. }
$$

The results obtained for the pair of variables A1 e A2 are described, with a 3 decimal digits approximation, in the following tables 1 and 2 :

Table 1. Matrix of geometrical means.

\begin{tabular}{c|c|c|l|c}
$\mathbf{G}^{\mathbf{A}}$ & $\mathbf{A 1}$ & $\mathbf{A 2}$ & & $\mathbf{P}^{\mathbf{A}}$ \\
\hline $\mathbf{A 1}$ & 1.000 & 6.926 & & 0.874 \\
\hline $\mathbf{A 2}$ & 0.144 & 1.000 & & 0.126
\end{tabular}

Table 2. Matrix of uncertainty indices.

\begin{tabular}{c|c|c|l|c}
$\mathbf{U}^{\mathbf{A}}$ & $\mathbf{A 1}$ & $\mathbf{A 2}$ & & $\mathbf{V}^{\mathbf{A}}$ \\
\hline $\mathbf{A 1}$ & 1.000 & 1.054 & & 1.027 \\
\hline $\mathbf{A 2}$ & 1.054 & 1.000 & & 1.027
\end{tabular}

The fuzzy numbers associate to A1 and A2 are:

$$
\begin{aligned}
& \mathrm{T}_{1}{ }^{\mathrm{A}}=(0.874 / 1.027,0.874,0.8741 .027)=(0.851,0.874,0.898) ; \\
& \mathrm{T}_{2}{ }^{\mathrm{A}}=(0.126 / 1.027,0.126,0.1261 .027)=(0.123,0.126,0.129),
\end{aligned}
$$

respectively. It is interesting to note that the maximum of left and right spreads are 0.023 , and 0.024 , respectively. This can be interpreted as a palatable agreement among the interviewed teachers about judgments on interpersonal communication and scholastic profit degree. 
The synthesis of the teachers' opinions on the pairwise comparisons of the variables B1, B2, .., B9 with respect to the sub-objective A1 are described in the following tables 3 and 4 .

The columns B1 to B9 of the table 3 define the matrix $G^{1}$ of the geometric means of opinions on the pairwise comparisons of the variables with respect to the sub-objective $\mathrm{A} 1$. The column $\mathrm{P}^{1}$ is the weighed arithmetic mean of the columns of $\mathrm{G}^{1}$, where every column has as weight the reciprocal of the sum of its elements.

The columns B1 to B9 of the table 4 define the matrix $\mathrm{U}^{1}$ of the indices of multiplicative uncertainty of the opinions. The column $\mathrm{V}^{1}$ is the geometrical mean of the columns of $\mathrm{U}^{1}$.

Table 3. Matrix of geometrical means w.r. to the sub-objective A1.

\begin{tabular}{|l|l|l|l|l|l|l|l|l|l|l|}
\hline $\mathbf{G}^{\mathbf{1}}$ & $\mathbf{B 1}$ & $\mathbf{B 2}$ & $\mathbf{B 3}$ & $\mathbf{B 4}$ & $\mathbf{B 5}$ & $\mathbf{B 6}$ & $\mathbf{B 7}$ & $\mathbf{B 8}$ & B9 $^{1}$ & $\mathbf{P}^{\mathbf{1}}$ \\
\hline B1 & 1.000 & 3.482 & 3.873 & 6.853 & 4.213 & 4.486 & 6.031 & 2.141 & 5.097 & 0.290 \\
\hline B2 & 0.287 & 1.000 & 2.590 & 7.000 & 5.207 & 4.787 & 3.708 & 2.141 & 4.486 & 0.199 \\
\hline B3 & 0.258 & 0.386 & 1.000 & 7.454 & 5.544 & 3.948 & 3.000 & 1.968 & 3.000 & 0.157 \\
\hline B4 & 0.146 & 0.143 & 0.134 & 1.000 & 1.088 & 0.880 & 1.732 & 0.919 & 1.000 & 0.045 \\
\hline B5 & 0.237 & 0.192 & 0.180 & 0.919 & 1.000 & 3.708 & 3.482 & 2.943 & 4.486 & 0.102 \\
\hline B6 & 0.223 & 0.209 & 0.253 & 1.136 & 0.270 & 1.000 & 1.968 & 2.432 & 3.201 & 0.068 \\
\hline B7 & 0.166 & 0.270 & 0.333 & 0.577 & 0.287 & 0.508 & 1.000 & 1.495 & 1.316 & 0.043 \\
\hline B8 & 0.467 & 0.467 & 0.508 & 1.088 & 0.340 & 0.411 & 0.669 & 1.000 & 2.817 & 0.063 \\
\hline B9 & 0.196 & 0.223 & 0.333 & 1.000 & 0.223 & 0.312 & 0.760 & 0.355 & 1.000 & 0.033 \\
\hline
\end{tabular}

Table 4. Matrix of uncertainty indices w.r. to the sub-objective A1.

\begin{tabular}{|l|l|l|l|l|l|l|l|l|l|r|}
\hline $\mathbf{U}^{1}$ & B1 & B2 & B3 & B4 & B5 & B6 & B7 & B8 & B9 & $\mathbf{V}^{1}$ \\
\hline B1 & 1.000 & 1.352 & 1.158 & 1.065 & 1.320 & 1.168 & 1.302 & 1.310 & 1.119 & 1.193 \\
\hline B2 & 1.352 & 1.000 & 1.299 & 1.306 & 1.437 & 1.424 & 1.355 & 1.333 & 1.157 & 1.289 \\
\hline B3 & 1.158 & 1.299 & 1.000 & 1.149 & 1.465 & 1.407 & 1.325 & 1.270 & 1.227 & 1.248 \\
\hline B4 & 1.065 & 1.306 & 1.149 & 1.000 & 1.656 & 1.655 & 1.402 & 1.564 & 1.623 & 1.357 \\
\hline B5 & 1.320 & 1.437 & 1.465 & 1.656 & 1.000 & 1.295 & 1.345 & 1.311 & 1.178 & 1.323 \\
\hline B6 & 1.168 & 1.424 & 1.407 & 1.655 & 1.295 & 1.000 & 1.286 & 1.298 & 1.336 & 1.308 \\
\hline B7 & 1.302 & 1.355 & 1.325 & 1.402 & 1.345 & 1.286 & 1.000 & 1.446 & 1.366 & 1.308 \\
\hline B8 & 1.310 & 1.333 & 1.270 & 1.564 & 1.311 & 1.298 & 1.446 & 1.000 & 1.350 & 1.312 \\
\hline B9 & 1.119 & 1.157 & 1.227 & 1.623 & 1.178 & 1.336 & 1.366 & 1.350 & 1.000 & 1.250 \\
\hline
\end{tabular}

The fuzzy numbers associate to B1, B2, .., B9, with respect to the sub-objective A1 are, respectively, the triangular fuzzy numbers (with a 3 decimal digits approximation):

$$
\begin{aligned}
& \mathrm{T}_{1}{ }^{1 \mathrm{~B}}=(0.290 / 1.193,0.290,0.2901 .193)=(0.243,0.290,0.346) ; \\
& \mathrm{T}_{2}{ }^{1 \mathrm{~B}}=(0.199 / 1.289,0.199,0.1991 .289)=(0.154,0.199,0.257) ; \\
& \mathrm{T}_{3}{ }^{1 \mathrm{~B}}=(0.157 / 1.248,0.157,0.1571 .248)=(0.126,0.157,0.196) ; \\
& \mathrm{T}_{4}{ }^{1 \mathrm{~B}}=(0.045 / 1.357,0.045,0.0451 .357)=(0.033,0.045,0.061) ; \\
& \mathrm{T}_{5}{ }^{1 \mathrm{~B}}=(0.102 / 1.323,0.102,0.1021 .323)=(0.077,0.102,0.135) ; \\
& \mathrm{T}_{6}{ }^{1 \mathrm{~B}}=(0.068 / 1.308,0.068,0.0681 .308)=(0.052,0.068,0.089) ;
\end{aligned}
$$


A. Maturo, R.M. Contini/ Application of the Analytic Hierarchy Process to the Sociological Analysis

$$
\begin{aligned}
& \mathrm{T}_{7}{ }^{1 \mathrm{~B}}=(0.043 / 1.308,0.043,0.0431 .308)=(0.033,0.043,0.056) ; \\
& \mathrm{T}_{8}{ }^{1 \mathrm{~B}}=(0.063 / 1.312,0.063,0.0631 .312)=(0.048,0.063,0.083) ; \\
& \mathrm{T}_{9}{ }^{1 \mathrm{~B}}=(0.033 / 1.312,0.033,0.0331 .312)=(0.025,0.033,0.043) \text {. }
\end{aligned}
$$

The synthesis of the teachers' opinions on the pairwise comparisons of the variables B1, B2, .., B9 with respect to the sub-objective A2 are described in the following tables 5 and 6.

Table 5. Matrix of geometrical means w.r. to the sub-objective A2.

\begin{tabular}{|l|l|l|l|l|l|l|l|l|l|c|}
\hline $\mathbf{G}^{2}$ & B1 & B2 & B3 & B4 & B5 & B6 & B7 & B8 & B9 & P $^{\mathbf{2}}$ \\
\hline B1 & 1.000 & 4.939 & 5.853 & 6.634 & 2.209 & 1.846 & 3.069 & 2.618 & 6.037 & 0.282 \\
\hline B2 & 0.202 & 1.000 & 1.358 & 4.394 & 1.032 & 1.135 & 1.510 & 1.345 & 2.141 & 0.103 \\
\hline B3 & 0.171 & 0.706 & 1.000 & 5.777 & 3.003 & 2.761 & 2.879 & 2.675 & 4.394 & 0.165 \\
\hline B4 & 0.151 & 0.228 & 0.173 & 1.000 & 1.066 & 1.000 & 1.403 & 1.122 & 1.495 & 0.057 \\
\hline B5 & 0.453 & 0.969 & 0.333 & 0.938 & 1.000 & 2.675 & 3.708 & 2.790 & 6.164 & 0.132 \\
\hline B6 & 0.542 & 0.881 & 0.362 & 1.000 & 0.374 & 1.000 & 3.555 & 3.559 & 5.604 & 0.113 \\
\hline B7 & 0.326 & 0.662 & 0.347 & 0.713 & 0.270 & 0.281 & 1.000 & 1.560 & 3.303 & 0.058 \\
\hline B8 & 0.382 & 0.743 & 0.374 & 0.891 & 0.358 & 0.281 & 0.641 & 1.000 & 5.373 & 0.063 \\
\hline B9 & 0.166 & 0.467 & 0.228 & 0.669 & 0.162 & 0.178 & 0.303 & 0.186 & 1.000 & 0.026 \\
\hline
\end{tabular}

Table 6. Matrix of uncertainty indices w.r. to the sub-objective A2.

\begin{tabular}{|l|l|l|l|l|l|l|l|l|l|c|}
\hline $\mathbf{U}^{2}$ & B1 & B2 & B3 & B4 & B5 & B6 & B7 & B8 & B9 & $\mathbf{V}^{2}$ \\
\hline B1 & 1.000 & 1.259 & 1.079 & 1.133 & 1.519 & 1.436 & 1.447 & 1.329 & 1.107 & 1.244 \\
\hline B2 & 1.259 & 1.000 & 1.571 & 1.270 & 1.590 & 1.587 & 1.406 & 1.469 & 1.500 & 1.392 \\
\hline B3 & 1.079 & 1.532 & 1.000 & 1.305 & 1.288 & 1.248 & 1.360 & 1.323 & 1.270 & 1.259 \\
\hline B4 & 1.133 & 1.270 & 1.305 & 1.000 & 1.653 & 1.618 & 1.576 & 1.522 & 1.527 & 1.382 \\
\hline B5 & 1.519 & 1.590 & 1.288 & 1.653 & 1.000 & 1.323 & 1.355 & 1.342 & 1.129 & 1.340 \\
\hline B6 & 1.436 & 1.587 & 1.248 & 1.618 & 1.323 & 1.000 & 1.343 & 1.317 & 1.148 & 1.322 \\
\hline B7 & 1.447 & 1.406 & 1.360 & 1.576 & 1.355 & 1.343 & 1.000 & 1.474 & 1.315 & 1.355 \\
\hline B8 & 1.329 & 1.469 & 1.323 & 1.522 & 1.342 & 1.317 & 1.474 & 1.000 & 1.267 & 1.329 \\
\hline B9 & 1.107 & 1.500 & 1.270 & 1.527 & 1.129 & 1.148 & 1.315 & 1.267 & 1.000 & 1.240 \\
\hline
\end{tabular}

The fuzzy numbers associate to B1, B2, .., B9, with respect to the sub-objective A2, are, respectively, the triangular fuzzy numbers (with a 3 decimal digits approximation):

$$
\begin{aligned}
& \mathrm{T}_{1}{ }^{2 \mathrm{~B}}=(0.282 / 1.244,0.282,0.2821 .244)=(0.227,0.282,0.351) ; \\
& \mathrm{T}_{2}{ }^{2 \mathrm{~B}}=(0.103 / 1.392,0.103,0.1031 .392)=(0.074,0.103,0.143) ; \\
& \mathrm{T}_{3}{ }^{2 \mathrm{~B}}=(0.165 / 1.259,0.165,0.1651 .259)=(0.131,0.165,0.208) ; \\
& \mathrm{T}_{4}{ }^{2 \mathrm{~B}}=(0.057 / 1.382,0.057,0.0571 .382)=(0.041,0.057,0.079) ; \\
& \mathrm{T}_{5}{ }^{2 \mathrm{~B}}=(0.132 / 1.340,0.132,0.1321 .340)=(0.099,0.132,0.177) ; \\
& \mathrm{T}_{6}{ }^{2 \mathrm{~B}}=(0.113 / 1.322,0.113,0.1131 .322)=(0.085,0.113,0.149) ; \\
& \mathrm{T}_{7}{ }^{2 \mathrm{~B}}=(0.058 / 1.355,0.058,0.0581 .355)=(0.043,0.058,0.079) ; \\
& \mathrm{T}_{8}{ }^{2 \mathrm{~B}}=(0.063 / 1.329,0.063,0.0631 .329)=(0.047,0.063,0.084) ; \\
& \mathrm{T}_{9}{ }^{2 \mathrm{~B}}=(0.026 / 1.240,0.026,0.0261 .240)=(0.021,0.026,0.032) \text {. }
\end{aligned}
$$


Finally we obtain the fuzzy scores $\mathrm{s}(\mathrm{BI})$ of the variables $\mathrm{BI}, \mathrm{I}=1,2, \ldots, 9$ by the formula:

$$
\mathrm{s}(\mathrm{BI})=\mathrm{T}_{1}^{\mathrm{A}} \mathrm{T}_{\mathrm{I}}^{1 \mathrm{~B}}+\mathrm{T}_{2}^{\mathrm{A}} \mathrm{T}_{\mathrm{I}}^{2 \mathrm{~B}},
$$

where we consider as addition the Zadeh addition of fuzzy numbers, based on the Extension Principle (Zadeh, 1975a; Zadeh, 1975b;), while the multiplication is the triangular approximation of the Zadeh multiplication, i.e., we replace the Zadeh product with the triangular fuzzy number having the same core and the same support. Then we obtain the following triangular fuzzy scores:

$$
\begin{aligned}
& \mathrm{s}(\mathrm{B} 1)=(0.851,0.874,0.898)(0.243,0.290,0.346)+(0.123,0.126,0.129)(0.227,0.282,0.351)=(0.235,0.289,0.356) ; \\
& \mathrm{s}(\mathrm{B} 2)=(0.851,0.874,0.898)(0.154,0.199,0.257)+(0.123,0.126,0.129)(0.074,0.103,0.143)=(0.140,0.187,0.249) ; \\
& \mathrm{s}(\mathrm{B} 3)=(0.851,0.874,0.898)(0.126,0.157,0.196)+(0.123,0.126,0.129)(0.131,0.165,0.208)=(0.123,0.158,0.203) ; \\
& \mathrm{s}(\mathrm{B} 4)=(0.851,0.874,0.898)(0.033,0.045,0.061)+(0.123,0.126,0.129)(0.041,0.057,0.079)=(0.033,0.047,0.065) ; \\
& \mathrm{s}(\mathrm{B} 5)=(0.851,0.874,0.898)(0.077,0.102,0.135)+(0.123,0.126,0.129)(0.099,0.132,0.177)=(0.078,0.106,0.144) ; \\
& \mathrm{s}(\mathrm{B} 6)=(0.851,0.874,0.898)(0.052,0.068,0.089)+(0.123,0.126,0.129)(0.085,0.113,0.149)=(0.055,0.074,0.099) ; \\
& \mathrm{s}(\mathrm{B} 7)=(0.851,0.874,0.898)(0.033,0.043,0.056)+(0.123,0.126,0.129)(0.043,0.058,0.079)=(0.033,0.045,0.060) ; \\
& \mathrm{s}(\mathrm{B} 8)=(0.851,0.874,0.898)(0.048,0.063,0.083)+(0.123,0.126,0.129)(0.047,0.063,0.084)=(0.047,0.063,0.085) ; \\
& \mathrm{s}(\mathrm{B} 9)=(0.851,0.874,0.898)(0.025,0.033,0.043)+(0.123,0.126,0.129)(0.021,0.026,0.032)=(0.024,0.032,0.043) .
\end{aligned}
$$

\section{Conclusions}

By previous analysis we can underline that, in order to obtain the foreign students scholastic integration, in the opinion of the group of teachers, the most important variables are, in order of preference:

$\mathrm{B} 1=$ interaction and relations in class with peers;

$\mathrm{B} 2=$ relations in the extra-curricular time;

$\mathrm{B} 3=$ interaction and relations in class with teachers.

The sum of the correspondent fuzzy scores is:

$$
(0.235,0.289,0.356)+(0.140,0.187,0.249)+(0.123,0.158,0.203)=(0.498,0.634,0.808) \text {. }
$$

The fourth variable in order of importance is B5 = linguistic-expressive abilities. The global score of $\{\mathrm{B} 1$, $\mathrm{B} 2, \mathrm{~B} 3, \mathrm{~B} 5\}$ is:

$$
(0.498,0.634,0.808)+(0.078,0.106,0.144)=(0.576,0.740,0.952) .
$$

A marginal role is the one of the remaining variables:

$\mathrm{B} 4=$ relations with the belonging environment;

B6 = logic-mathematical abilities;

B7 = manual skills;

$\mathrm{B} 8$ = group activities;

$\mathrm{B} 9=$ sport skills.

In sec. 3 , as cores of the fuzzy scores, are taken the vectors $\mathrm{P}^{\mathrm{A}}, \mathrm{P}^{1}$, and $\mathrm{P}^{2}$, obtained as weighed means of the columns of the matrices $\mathrm{G}^{\mathrm{A}}, \mathrm{G}^{1}$, and $\mathrm{G}^{2}$, respectively. The aim of such choice is to give to scholars of Social Sciences a procedure that utilizes the minimal set of mathematical tools.

As it is suggested, with many logical and mathematical motivations, by Saaty in (Saaty, 1980; Saaty, 2008), it is preferable to replace $\mathrm{P}^{\mathrm{A}}, \mathrm{P}^{1}$, and $\mathrm{P}^{2}$, with the normalized eigenvectors $\mathrm{E}^{\mathrm{A}}, \mathrm{E}^{1}$, and $\mathrm{E}^{2}$ associated to the principal eigenvalues $\lambda^{\mathrm{A}}, \lambda^{1}$, and $\lambda^{2}$, of the matrices $\mathrm{G}^{\mathrm{A}}, \mathrm{G}^{1}$, and $\mathrm{G}^{2}$, respectively. 
Moreover, if $\mathrm{n}$ is the number of objects submitted to pairwise comparisons and $\lambda$ is the principal eigenvalue of the paired comparisons matrix, Saaty suggests to consider the following consistence index:

$$
\mu=(\lambda-n) /(n-1)
$$

As to the matrix $\mathrm{G}^{\mathrm{A}}$, of order 2 , the consistence is evident, $\lambda^{\mathrm{A}}=2, \mu=0$, and $\mathrm{P}^{\mathrm{A}}=\mathrm{E}^{\mathrm{A}}$.

Let us consider the matrices $G^{1}$ and $G^{2}$. The following table 7 shows the principal eigenvalues, the correspondent normalized eigenvectors, and the values of consistence index, and weighed arithmetic means of the columns, for these matrices.

Table 7. Eigenvalues, eigenvectors, and consistence indices.

\begin{tabular}{|l|l|l|l|l|}
\hline & $\boldsymbol{\lambda}$ & $\mathbf{E}$ & $\boldsymbol{\mu}$ & $\mathbf{P}$ \\
\hline $\mathbf{G}^{\mathbf{1}}$ & \multirow{2}{*}{10.344} & $(0.303,0.211,0.164$, & 0.168 & $(0.290,0.199,0.157$, \\
& & $0.042,0.090,0.058$, & & $0.045,0.102,0.068$, \\
& & $0.039,0.057,0.031)$ & & $0.043,0.063,0.033)$ \\
\hline $\mathbf{G}^{\mathbf{2}}$ & \multirow{2}{*}{10.306} & $(0.302,0.107,0.165$, & 0.163 & $(0.282,0.103,0.165$, \\
& & $0.055,0.124,0.104$, & & $0.057,0.132,0.113$, \\
& & $0.054,0.059,0.025)$ & & $0.058,0.063,0.026)$ \\
\hline
\end{tabular}

By table 7, we can observe that there are not considerable differences between the vectors $\mathrm{E}$ and the vectors $\mathrm{P}$, then the procedure based on eigenvalues and eigenvectors confirms the results obtained in sec. 3. Moreover the correspondent consistence indices seem to be good, especially in the light of the fact that matrices $G^{1}$ and $G^{2}$ are results of opinions of a group, that in general, have a degree of inconsistence greater than the opinions of a single decision maker.

\section{REFERENCES}

Ambrosini, M. (2008a), Un'altra globalizzazione, Il Mulino, Bologna.

Ambrosini, M. (2008b), Il futuro in mezzo a noi: la sfida delle nuove generazioni di origine immigrata, relazione nel Convegno Nazionale I giovani immigrati e le loro famiglie, organizzato dall'Osservatorio Nazionale sulla famiglia, sede di Bologna, Ancona 27 novembre 2008

Ambrosini, M. (2007), Integrazione e multiculturalismo: una falsa alternativa, in «Mondi Migranti, Rivista di studi e ricerche sulle migrazioni internazionali», a.1, n. 1.

Barbagli, M. (2006), L’integrazione scolastica delle seconde generazioni di stranieri nelle scuole secondarie di primo grado della Regione Emilia Romagna, Osserv. sulle differenze, Com. Bologna.

Bauman, Z. (1999), Dentro la globalizzazione, Laterza. Roma-Bari.

Bauman, Z. (1999a), La società dell'incertezza, Il Mulino, Bologna.

Bauman, Z. (1999b), Dentro la globalizzazione, Laterza, Roma-Bari.

Bauman, Z. (2001), Voglia di comunità, Laterza, Roma-Bari. 
Besozzi, E. (2001), L'incontro tra culture e la possibile convivenza, Studi di sociologia, Anno XXXVIII, Gennaio-Marzo 2001, Vita e Pensiero, 64-81.

Besozzi, E. (2006), Società, cultura, educazione, Teorie, contesti, processi, Carocci, Roma.

Cesareo, V. (2004) (a cura di), L'Altro, Identità, dialogo e conflitto nella società plurale, Vita e Pensiero, Milano.

Cesareo, V. (2008), Migrazioni 2007: uno sguardo d'insieme, in Fondazione Ismu, Tredicesimo rapporto sulle migrazioni 2007, Franco Angeli, Milano, 7-38

Dubet F., \& Martuccelli D. (1996), A l'école, Sociologie de l'expérience scolaire, Seuil.

Featherstone, M. (1996), Cultura globale, Seam, Roma.

Geertz, C. (1999), Mondo globale, mondi locali, Il Mulino, Bologna.

Giovannini G., \& Palmas L. Q. (2002) (a cura di), Una scuola in comune, Esperienze scolastiche in contesti multietnici italiani, Torino, Edizioni Fondazione Giovanni Agnelli.

Klir G., \& Yuan B. (1995), Fuzzy sets and fuzzy logic: Theory and Applications, Prentice Hall, New Jersey.

Kosko, B. (1995). Il fuzzy-pensiero, Teoria e applicazioni della logica fuzzy, Baldini\&Castaldi, Milano,

Kristeva, J. (1990), Stranieri a noi stessi, Feltrinelli, Milano.

Portes A., \& Hao L. (2002), The price of uniformity: Language, family and personality adjustment in the immigrant Second generation, in Ethnic and Racial Studies, 25, pp. 889-912.

Portes A., \& Rumbaut R.G. (2001), Legacies, The story of the migrant second generation, Berkeley-New York, University of California Press-Russel Sage Foundation.

Portes A., \& Zhou M. (1993), The new second generation, Segmented assimilation and its variants, In Annals of the American Accademy of Political and Social Sciences, 530 pp, 74-96.

Saaty, T. L. (1980), The Analytic Hierarchy Process, McGraw-Hill, New York.

Saaty. T.L.. \& Peniwati. K. (2007). Group decision-making: Drawing out and reconciling differences. Pittsburgh. PA: RWS Publications.

Saaty, T.L., \& Shang, J.S. (2007), Group decision-making: Head-count versus intensity of preference, Socio-Economic Planning Sciences, 41, 22-37.

Saaty, T.L., (2008), Relative Measurement and Its Generalization in Decision Making, Why Pairwise Comparisons are Central in Mathematics for the Measurement of Intangible Factors, The Analytic Hierarchy/Network Process, Rev. R. Acad. Cien. Serie A. Mat., Vol. 102 (2), 251-318. 
A. Maturo, R.M. Contini/ Application of the Analytic Hierarchy Process to the Sociological Analysis

Zadeh, L., (1975a), The Concept of a Linguistic Variable and its Application to Approximate Reasoning I and II, Information Sciences, 8, p. 199-249 and p. 301-357.

Zadeh, L., (1975b), The Concept of a Linguistic Variable and its Applications to Approximate reasoning III, Information Sciences 9, p. 43-80. 